$$
\text { DOENDC/ } 30214-\text { - T } 3
$$

Progress Report for Research on

\title{
etro
}

DE82 011699

HEAT TRANSFER TO TUBES

IN FREEBOARD SPACE OF FLUIDIZED-BED COMBUSTORS

\section{Period of}

August 1, 1981 to January 31, 1982

Professor John C. Chen

Suleyman Biyik1i (Research Assistant)

$$
\text { FG22-80PC 30214 }
$$

Department of Mechanical Engineering

and Mechanics

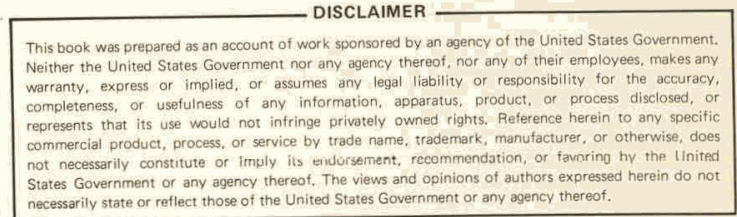

LEHIGH UNIVERSITY

Bethlehem, Pa. 18015

February 1982 


\section{DISCLAIMER}

This report was prepared as an account of work sponsored by an agency of the United States Government. Neither the United States Government nor any agency Thereof, nor any of their employees, makes any warranty, express or implied, or assumes any legal liability or responsibility for the accuracy, completeness, or usefulness of any information, apparatus, product, or process disclosed, or represents that its use would not infringe privately owned rights. Reference herein to any specific commercial product, process, or service by trade name, trademark, manufacturer, or otherwise does not necessarily constitute or imply its endorsement, recommendation, or favoring by the United States Government or any agency thereof. The views and opinions of authors expressed herein do not necessarily state or reflect those of the United States Government or any agency thereof. 


\section{DISCLAIMER}

Portions of this document may be illegible in electronic image products. Images are produced from the best available original document. 
SCOPE OF THE PROJECT

The objective of the research is to carry out an experimental study of heat transfer characteristics for tubes located in the freeboard region of fluidized beds. The heat transfer coefficients will be measured and experimental techniques for determining solid-contact behavior on the surface of horizontal tubes will be evaluated. Data will be obtained for various bed particles over a range of fluidization air flow rates, and for a range of tube elevations. Tests will be performed in room temperature beds and in high temperature beds. The anticipated results are:

(a) Experimental data for heat transfer in freeboard region for single tubes; at room temperature and at $\mathrm{FBC}$ operating temperatures;

(b) Determination of effect of operating variables (gas velocity, tube elevation, particle size, particle density, etc.) on heat transfer coefficients;

(c) Indication of possible experimental method for determination of dominant heat transfer mechanisms in freeboard region, from solid contact measurements, in room temperature bed;

(d) Derivation of phenomenological models and correlations.

PROGRESS IN. THE PROJECT

This is the third progress report covering the period of August 1, 1981 to January 31 , 1982 .

\section{Task 1 Low Temperature Heat Transfer Experiments}

The objective of this task is to obtain heat transfer data on a horizontal tube in the freeboard region of a fluidized bed, operating at room temperature. The results of these experiments will help in filling some of the informational gaps on developing a phenomenological model.

As mentioned in previous reports, the new fluidized bed and the new heat transfer probe has been manufactured and assembled. During this 
progress report period, the heat transfer experiments and data reduction were completed. A schematic of the test setup is shown in Figure 1 . The static bed height was held constant at $36 \mathrm{~cm}$, except for the experiments for the effects of static bed height. The heat transfer tube was placed to the heights of $1.25,19,58,147$ and $224 \mathrm{~cm}$ above the bed. The 1.25 $\mathrm{cm}$ tube elevation was the one when the lower side of the tube just touched the top of the static bed. Immersed tube heat transfer coefficients were also measured (for glass beads of $\bar{d}=300,850 \mu \mathrm{m}$ ) to compare with the heat transfer coefficients in freeboard region. Glass beads with $300,850 \mu \mathrm{m}$ mean diameters and.sand with 285, 465 um mean diameters were used as fluidizing particles. High gas velocities were reached up to $3.5 \mathrm{~m} / \mathrm{sec}$. The heat transfer probe was capable to measure local heat transfer coefficients at eight locations that are $45^{\circ}$ apart from each other. The average heat transfer coefficients were then calculated by integrating the local values.

A sample of experimental results for the variation of local heat transfer coefficient around the heat transfer tube for glass beads with mean diameter $300 \mu \mathrm{m}$ is shown in Figures $2 \mathrm{a}$ and $2 \mathrm{~b}$ for low and high air flow rates. These experiments were also carried out for $850 \mu \mathrm{m}$ mean diameter glass beads and.285 and $465 \mu \mathrm{m}$ mean diameter sand.

Average heat transfer coefficients were calculated from above mentioned local experimental data. Effects of tube elevation and gas flow rate on average heat transfer coefficient is shown in Figure 3 . for glass beads with mean diameter of $300 \mathrm{\mu m}$. Experimental results for average heat transfer coefficient versus tube elevation are shown in Figures 4 and 5 for two different gas flow rates.

Effect of static bed height on heat transfer coefficient was also investigated by changing the static bed height. These experiments were carried out with only sand particles with mean diameters of $465 \mu \mathrm{m}$. Three different static bed heights were used which were 18,36 and $72 \mathrm{~cm}$. The heat transfer tubc was $19 \mathrm{~cm}$ above the static bed fur each of these bed heights. The results are shown in Figures 6 and 7 which indicate that heat transfer coefficients do not vary much after $36 \mathrm{~cm}$ bed height for all the gas flow rates. 


\section{Task 2 Dynamic Contact Experiments}

The capacitance probe technique was utilized in order to obtain measurements of dynamic contact of bed particles on the tube surface. These tests were carried out at three different angular positions, $\beta=0^{\circ}, 90^{\circ}$ and $180^{\circ}$, for GT-5, $d=850 \mu \mathrm{m}$, particles. The information will be used on developing a phenomenological model for the heat transfer:process, for horizontal tubes in freeboard region of $F B C^{\prime} s$.

The capacitance sensed by the probe is proportional to the dielectric constant of the fluidized medium local to the probe electrodes. The dielectric constant in turn depends on the local void fraction. Thus, a capacitance trace versus time can be directly related to the variations in local solids density at the tube surface. The measured capacitance signals were calibrated relative to an upper bound corresponding to the capacitance measured when the probe is immersed in a loosely packed static bed of particles, and a lower bound corresponding to the capacitance sensed when the probe is fully exposed to air. This calibration process was repeated at least for air (lower bound) before each experiment.

Examples of typical capacitance signals obtained with an instrumented horizontal tube immersed in a fluidized bed are shown in Figures $8 \mathrm{a}, 8 \mathrm{~b}$, and $8 \mathrm{c}$. These data were obtained for fluidization at atmospheric pressure. Figure $8 \mathrm{a}$ shows periodic particle contact at the bottom of the tube, for a gas flow rate corresponding to just above the fluidization flow rate. When the flow rate is increased, particles reach higher elevations and the bottom surface contact behavior is shown in Figure $8 \mathrm{~b}$. The particle surface contact behavior at the side of the tube is. shown in Figure $8 c$.

Samples of the reduced data are shown in Figures 9 and 10 . Figure 9 shows the variation of local voidage as a function of gas velocity, for different tube elevations and angular positions. Local residence times of particles on the tube surface is shown in Figure 10 as a function of gas velocity for different tube elevations and angular positions.

\section{Task 3 High Temperature Heat Transfer Experiments}

An instrumented heat exchanger has been designed and fabricated to measure the average heat transfer coefficients at different elevations in 
the freeboard region. The heat exchanger will be assembled into the high temperature fluidized bed facility and the tests will be carried out during the next report period. 


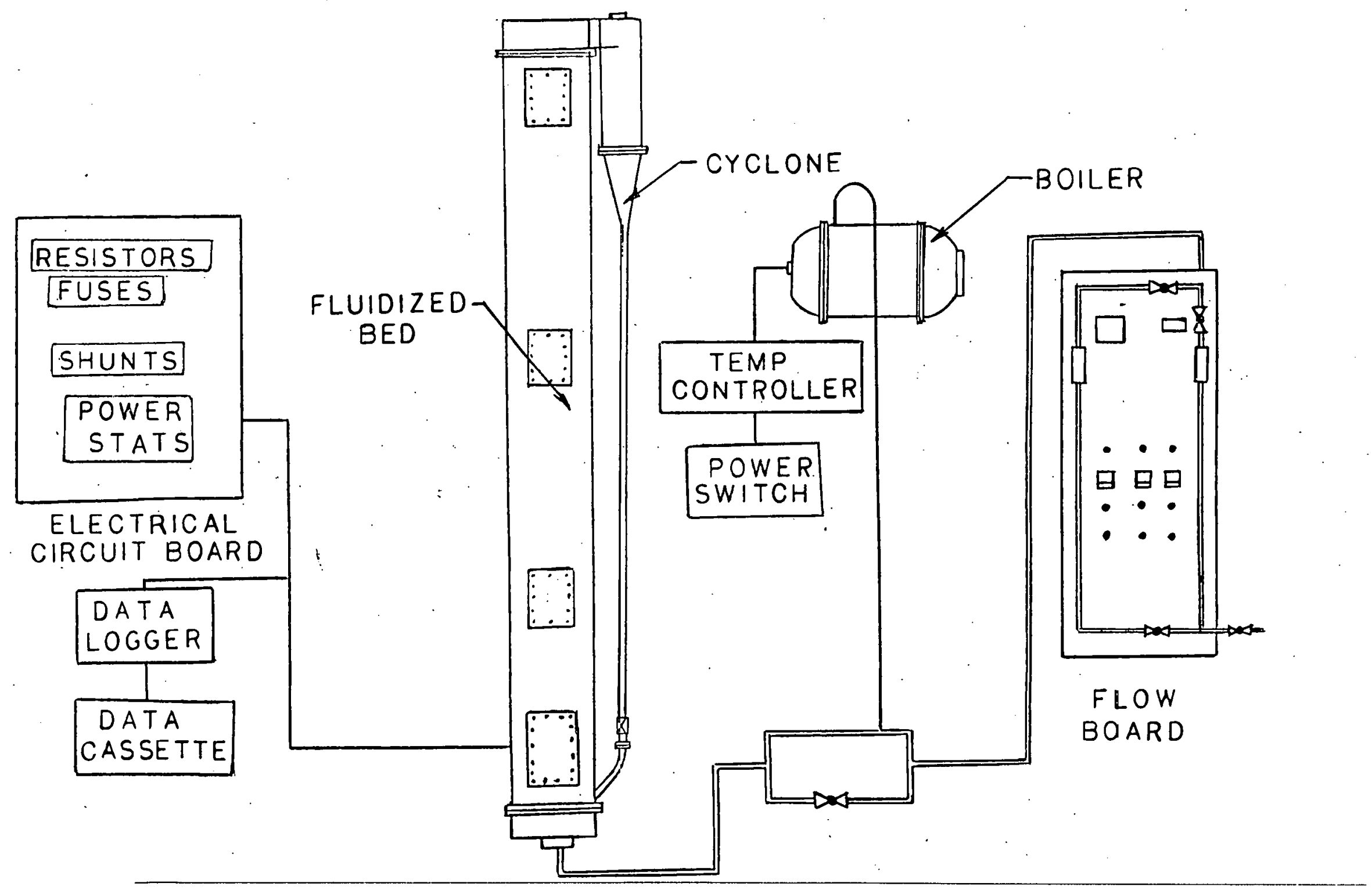

Figure 1 Flow diagram for the fluidized bed test unit 


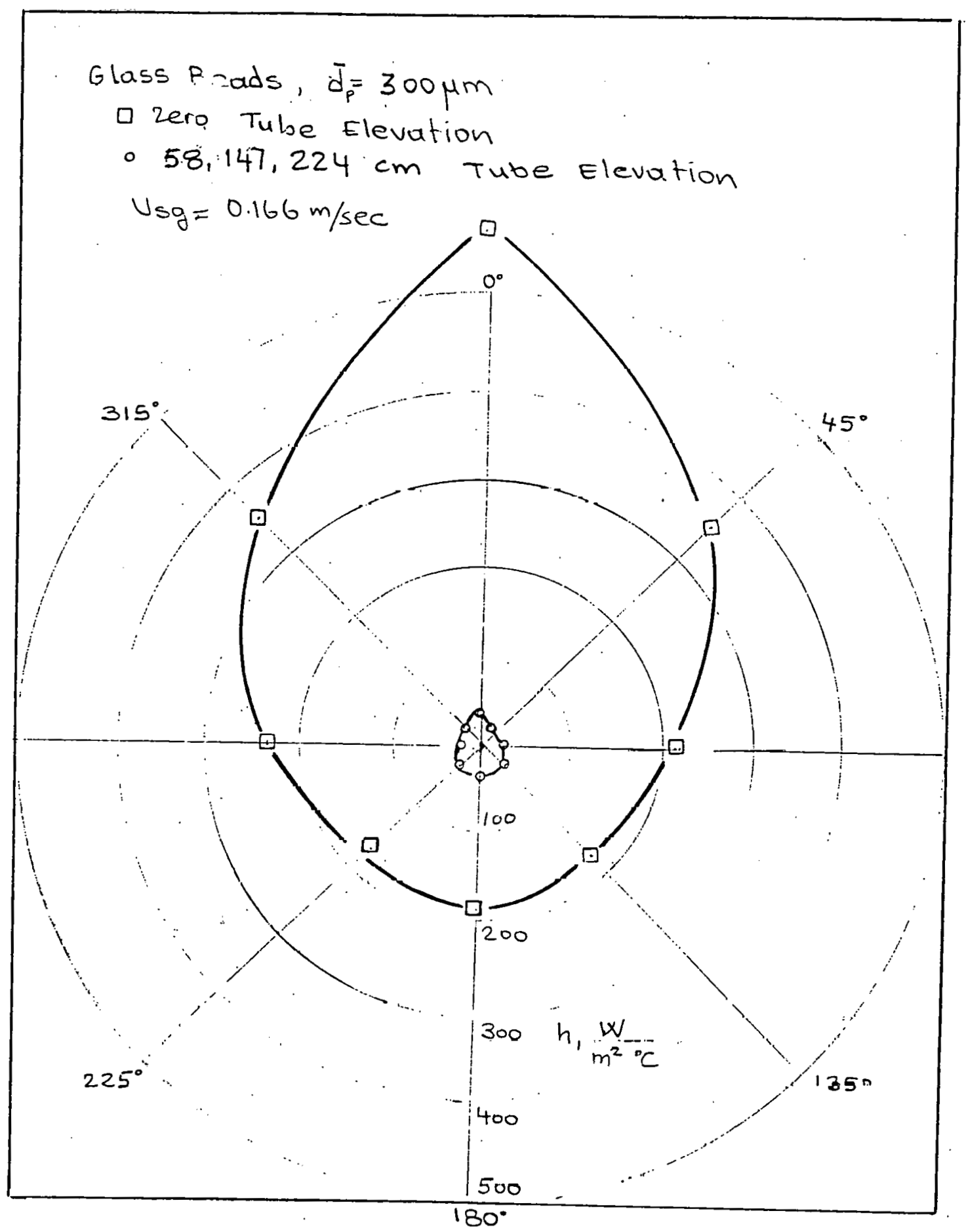

Figure $2 a$ Local heat transfer coefficient around the tube in freeboard region for $U_{S g}=0.166 \mathrm{~m} / \mathrm{sec}$ 
Glase beads. $\bar{d}_{p}=300 \mu m$

- 0 cm Tube elevation

- $58 \mathrm{~cm}$."

$\Delta 147 \mathrm{~cm}$."

$+224 \mathrm{~cm}$. "

$U_{s g}=2.50 \mathrm{~m} / \mathrm{sec}$

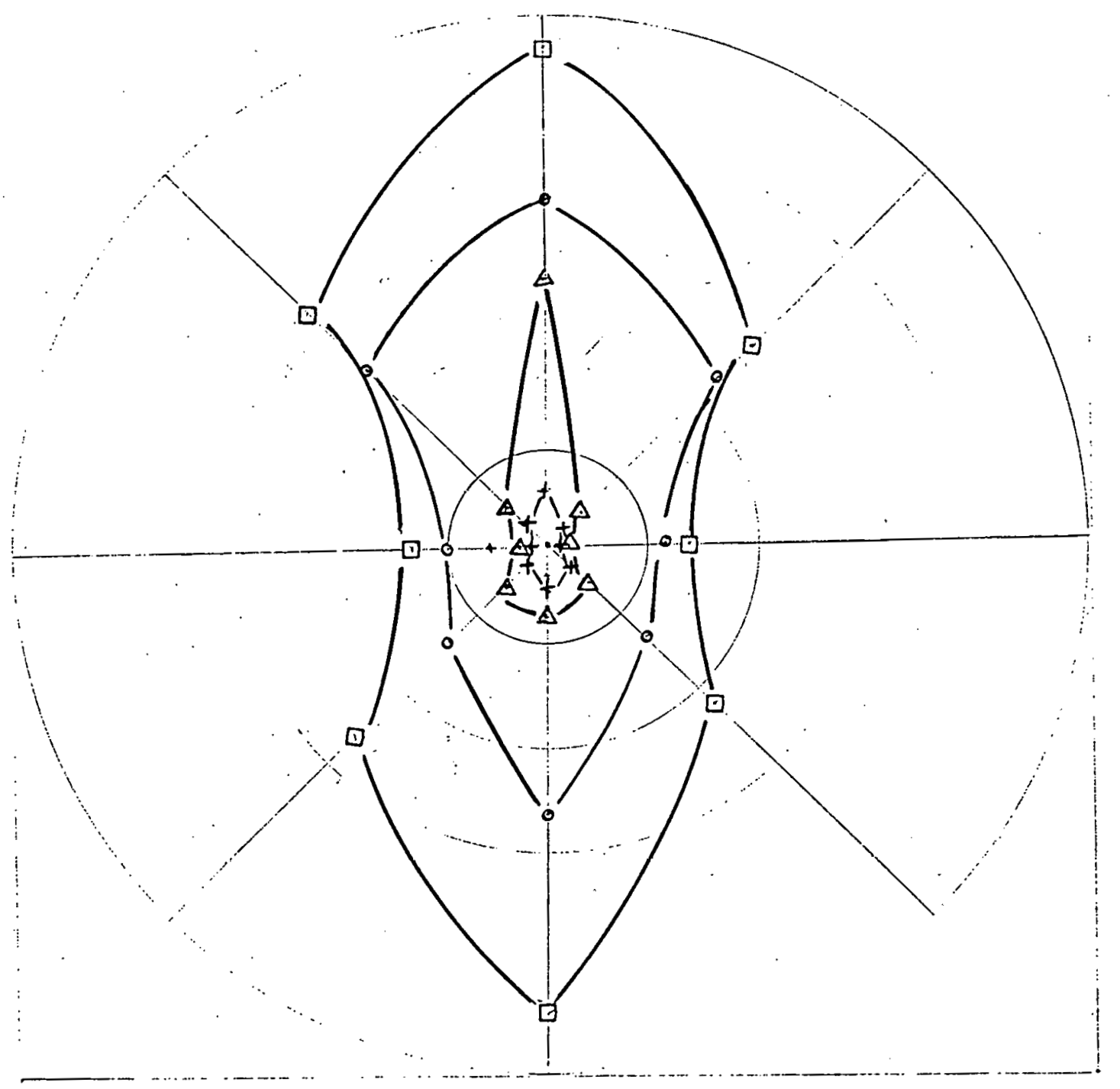

Figure $2 b$ Local heat transfer coefficient around the tube in freeboard region for $U_{S a}=2.50 \mathrm{~m} / \mathrm{sec}$ 


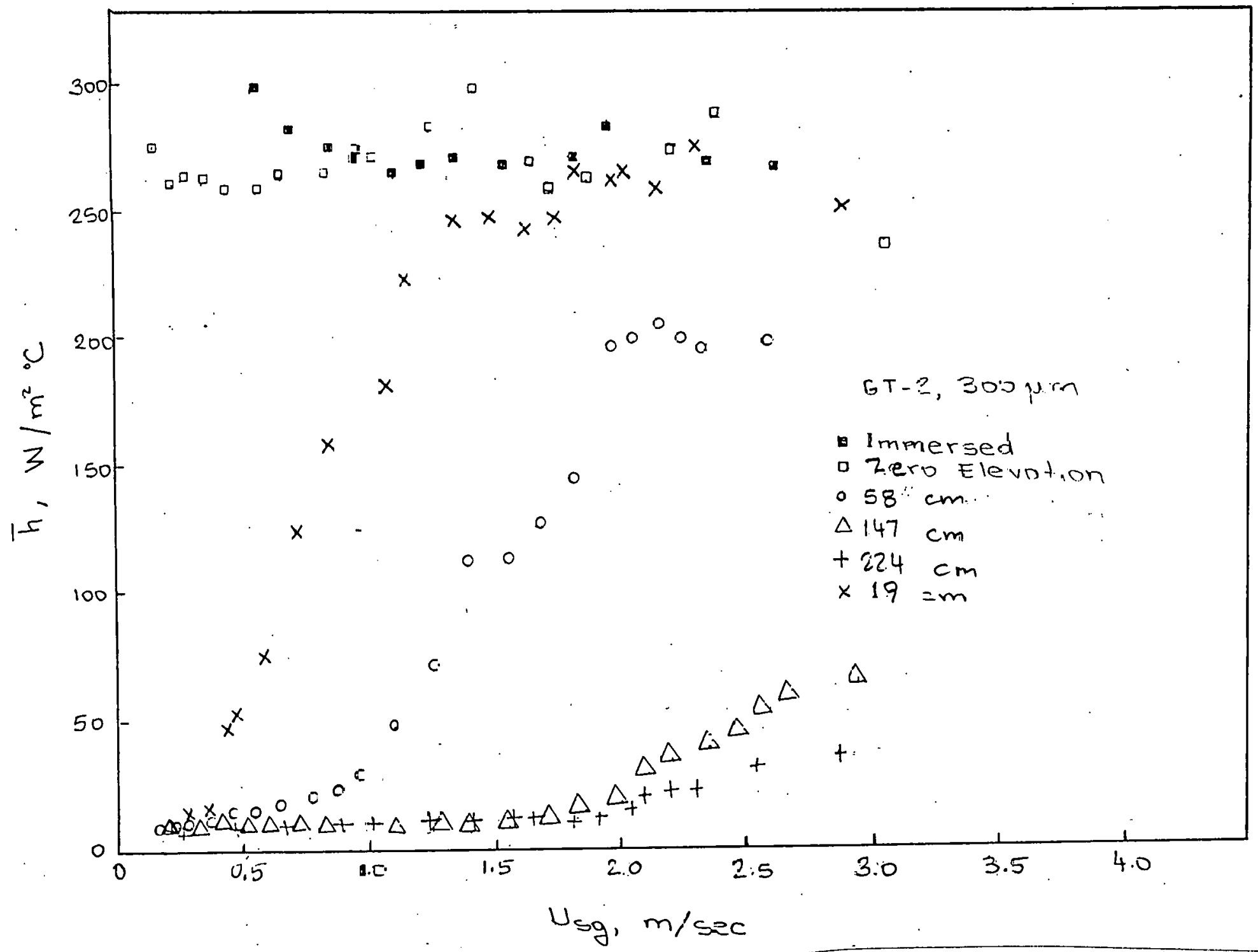

Figure 3 Freeboard heat transfer coef icients for glass beads with $300 \mu \mathrm{m}$ nean diameter 


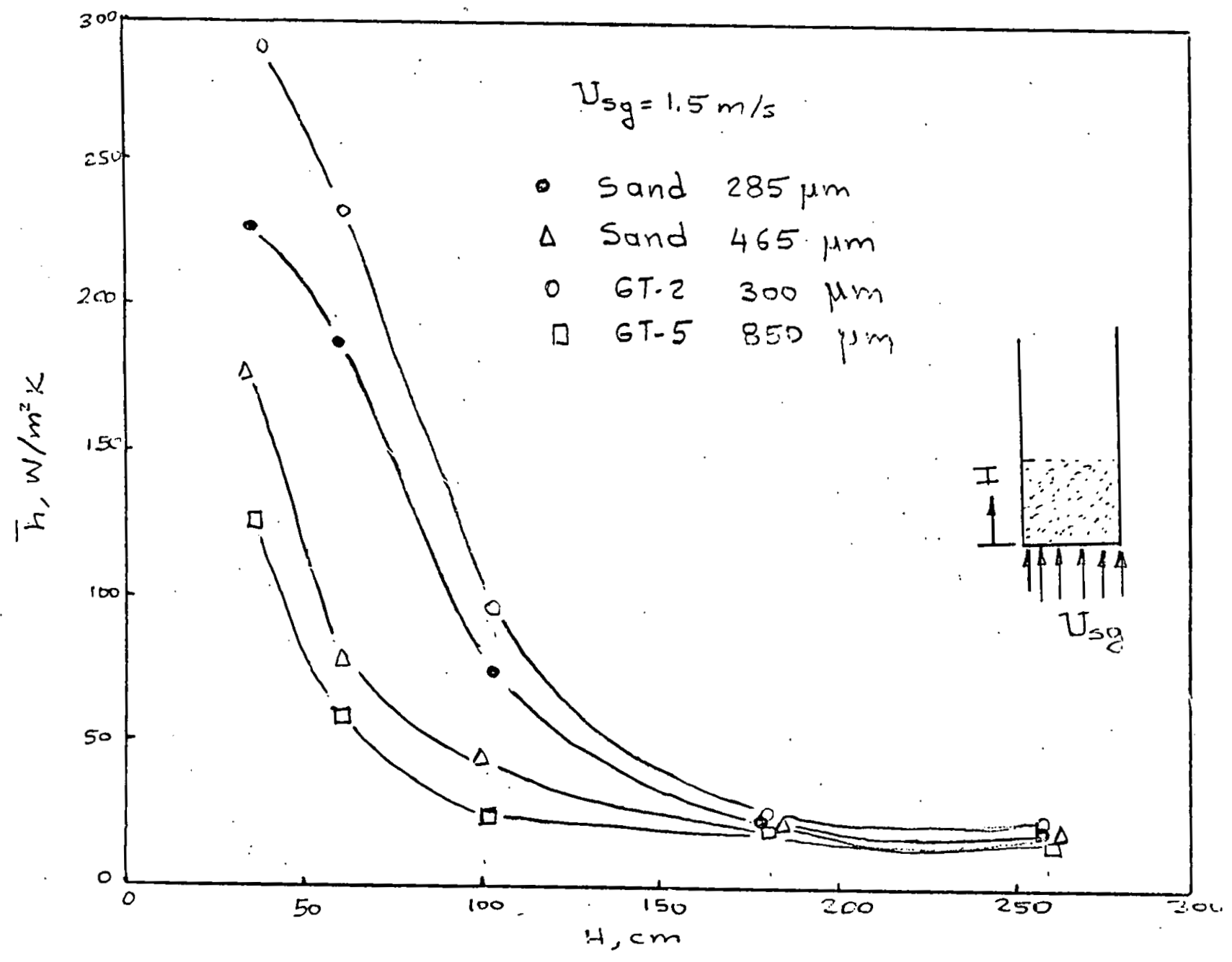

Figure 4 Variation of average heat transfer coefficient in the freeboard, at superficial gas velocity, $U_{\mathrm{sg}}=1.5 \mathrm{~m} / \mathrm{sec}$ 


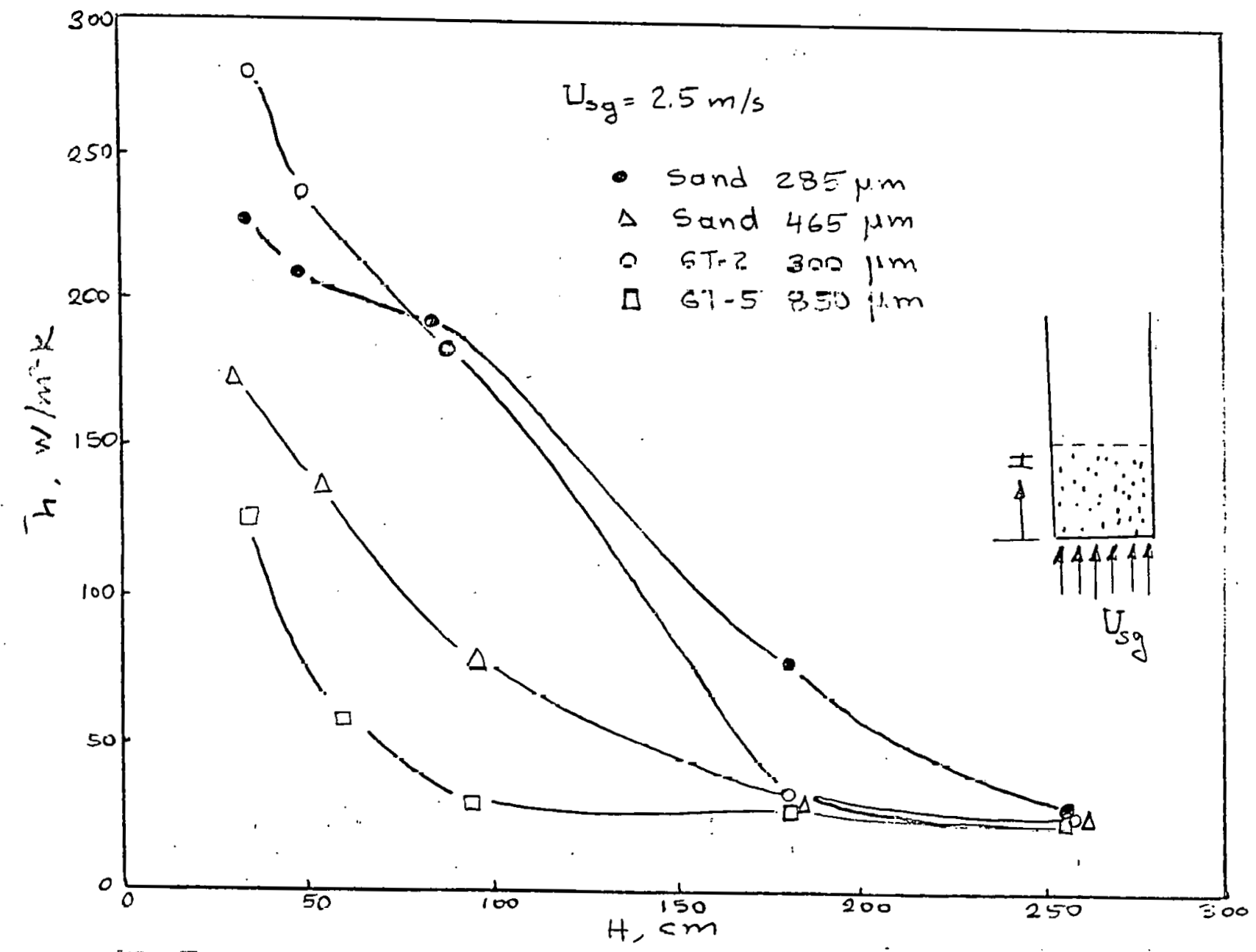

Figure 5 Variation of average heat transfer coefficient in the freeboard, at superficial gas velocity, $U_{\mathrm{sg}}=2.5 \mathrm{~m} / \mathrm{sec}$ 


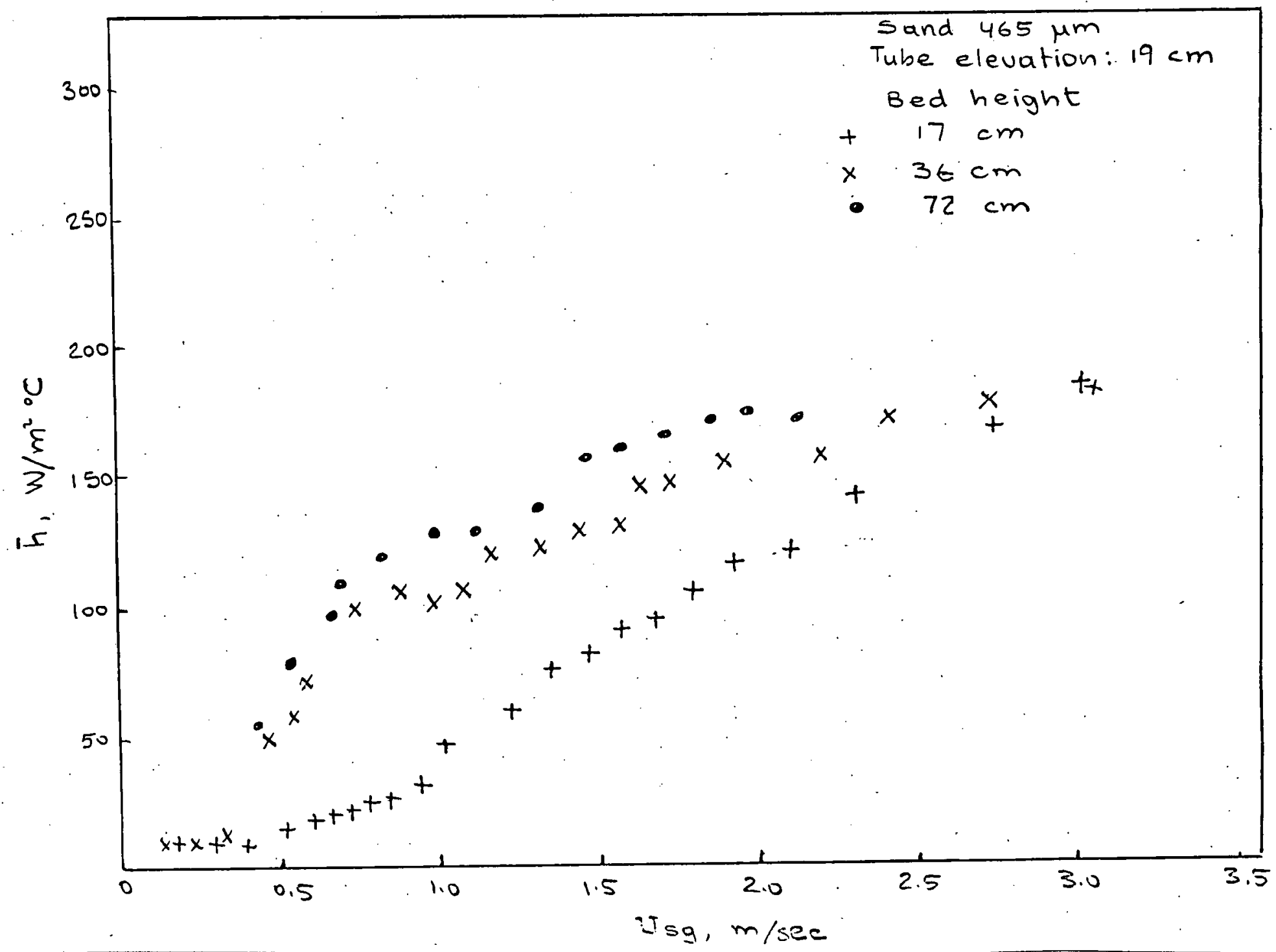

Figure 6 Effect of static bed height on heat transfer coefficients 


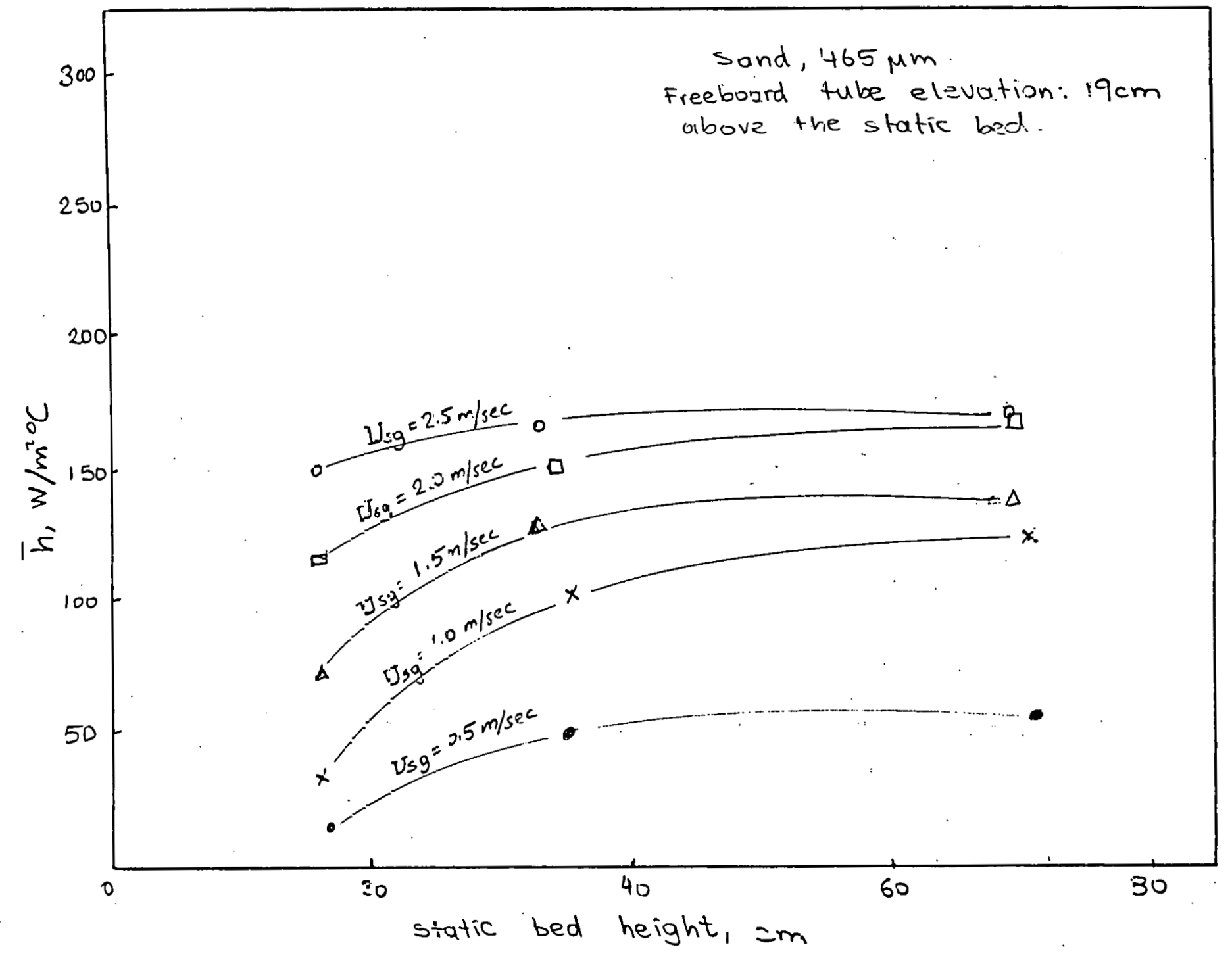

Figure 7 Effezt of static bed height on heat transfer ir freeboard region of the bed 


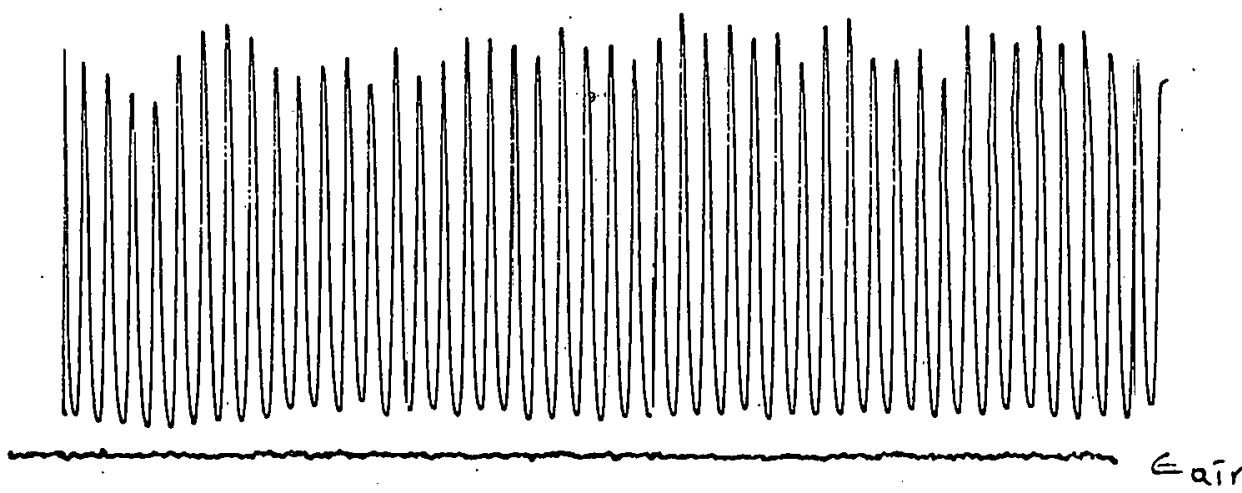

Figure 8a Capacitance signal at $U_{\mathrm{Sg}}=0.53 \mathrm{~m} / \mathrm{sec}$ gas velocity for GT-5, $d_{p}=850 \mu \mathrm{m}$, at the bottom of the tube, $\beta=180^{\circ}$. Tube just touches to the bed, $\mathrm{H}=1.25 \mathrm{~cm}$ 


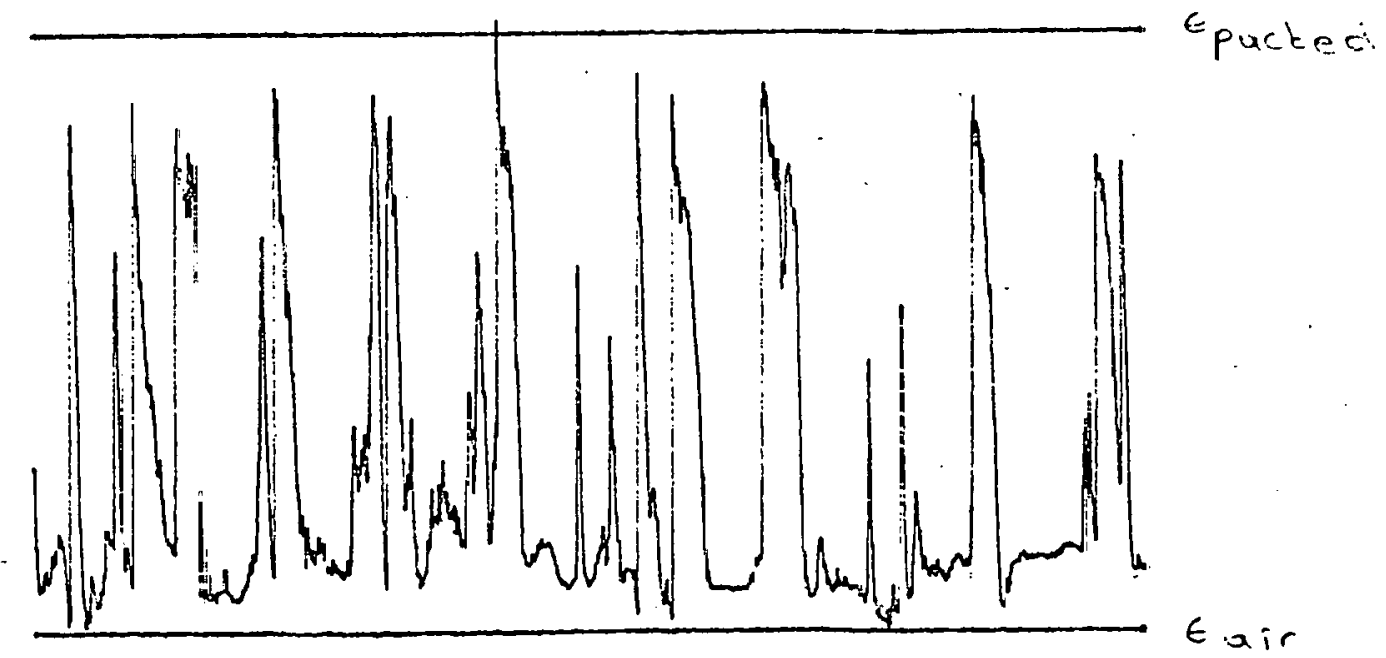

Figure $8 \mathrm{~b}$ Capacitance signal for $G T-5, \bar{d}_{p}=850$ pm at gas velocity $U_{S g}=2.55$ $\mathrm{m} / \mathrm{sec}$, at the bottom of the tube, $\beta=: 80^{\circ}$. Tube is $19 \mathrm{~cm}$ above the static bed 


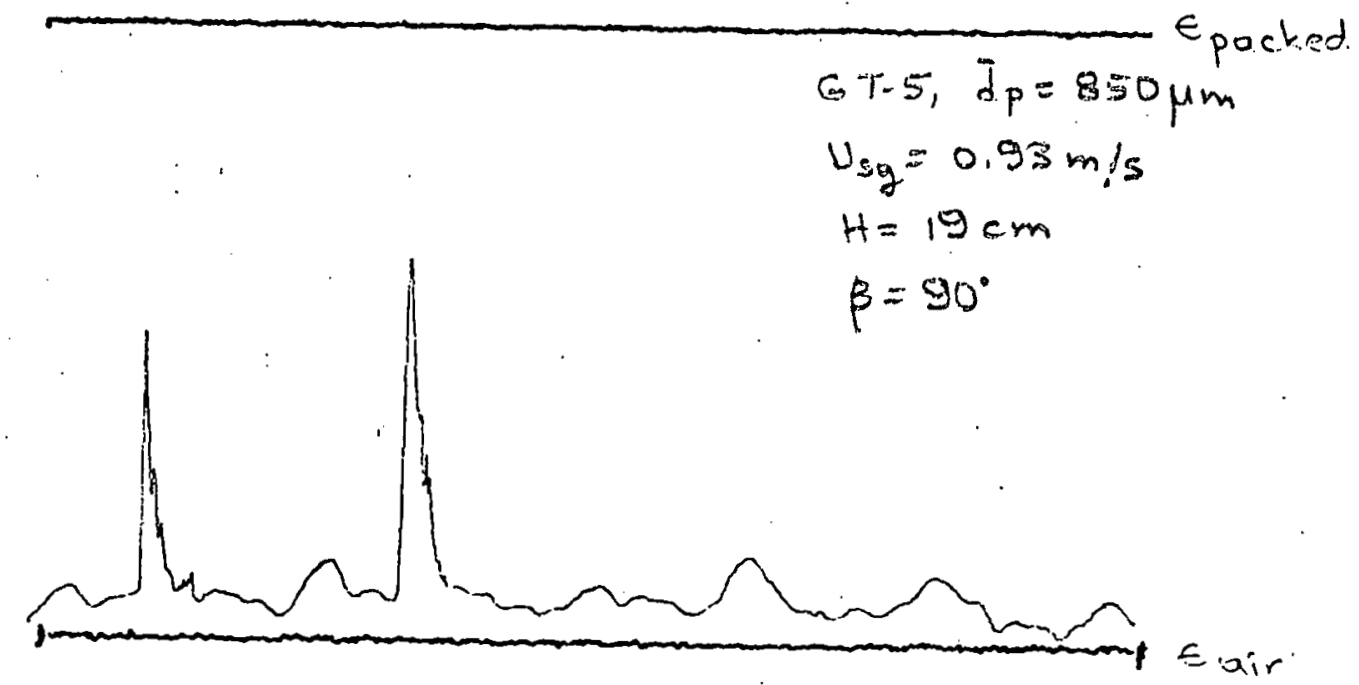

Figure $8 \mathrm{c}$ Capacitance signal for $\mathrm{GT}-5, \bar{d}_{p}=850 \mu \mathrm{m}$. At the second tube elevation, $\mathrm{H}=19 \mathrm{~cm}$ 


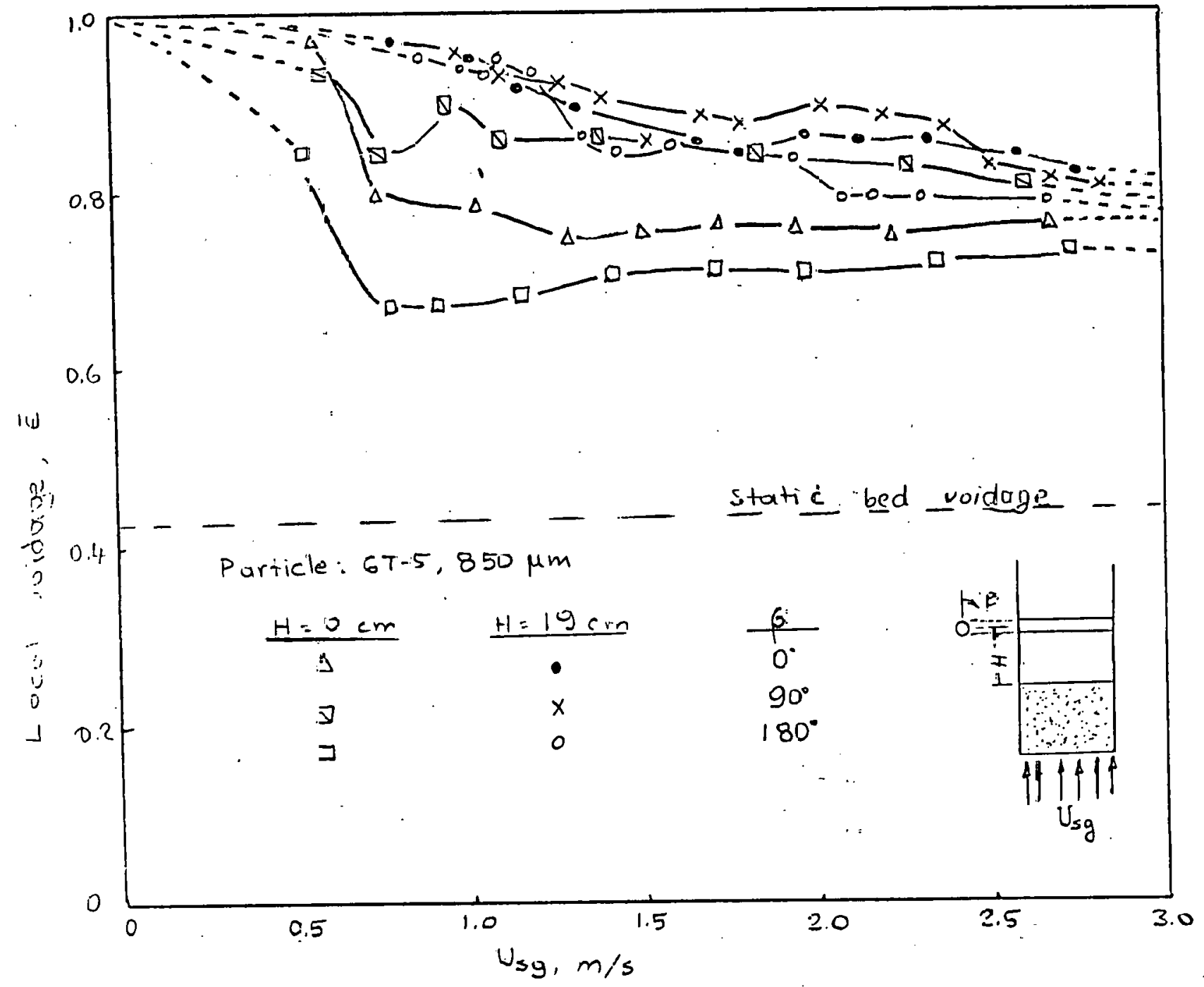

Figure 9 Local bed voidage as a function of gas veloci $y$ 


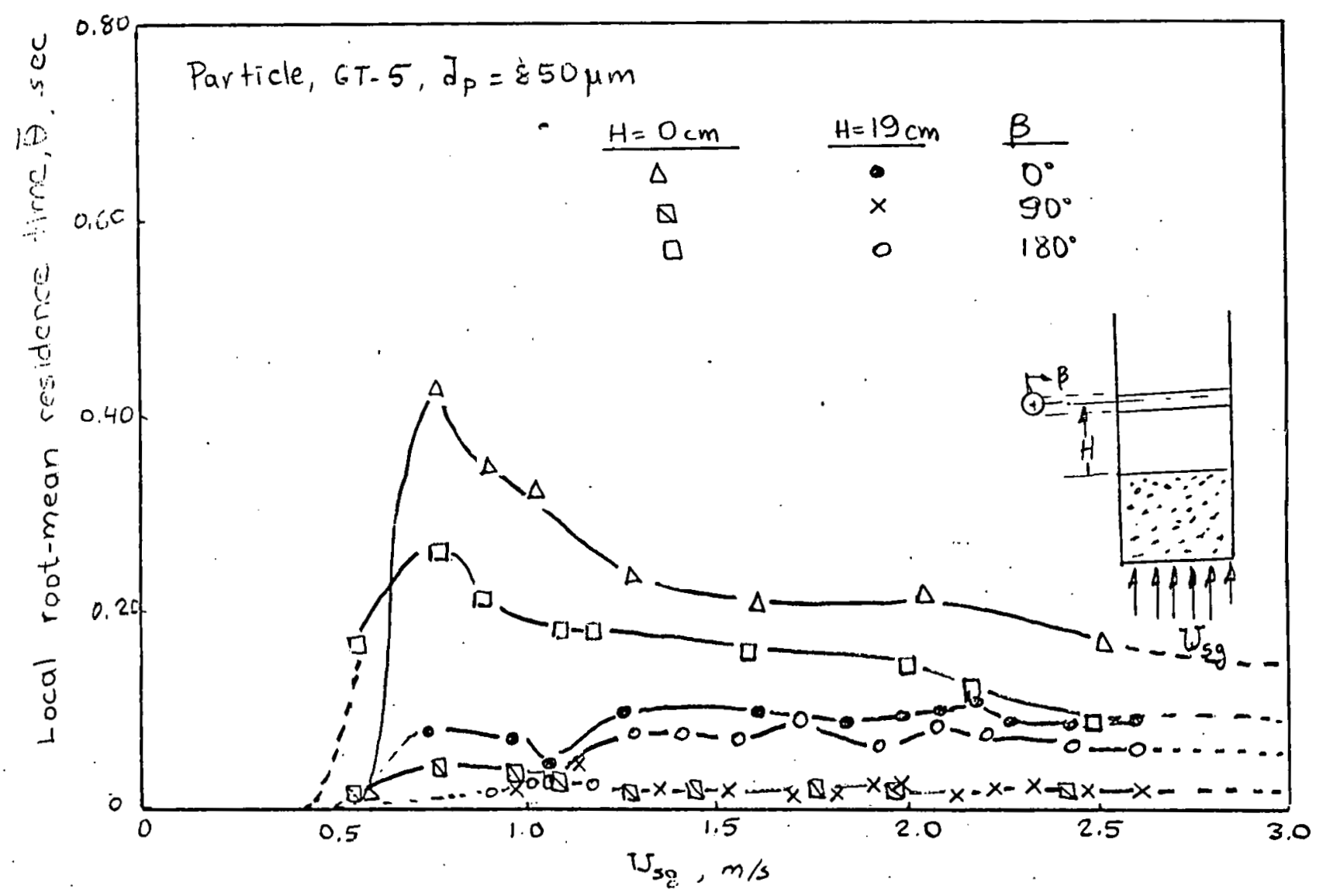

Figure 10 Local residence times of particles on the tube surface 